\title{
Factors Influencing Utilization of Cervical Cancer Screening Services in Kenya: The Case of Nyeri County
}

\author{
Gichogo Agnes Wangechi ${ }^{1}$, David Macharia ${ }^{2}$ \\ ${ }^{1}$ Reproductive Health Coordinator, Nyeri County, Kenya \\ ${ }^{2}$ Open, Distance and eLearning (ODeL) Campus, University of Nairobi, Kenya
}

\begin{tabular}{l} 
Article Info \\
\hline Article history: \\
Received Aug 13, 2018 \\
Revised Nov 6, 2018 \\
Accepted Nov 12, 2018 \\
\hline
\end{tabular}

Keyword:

Accessibility

Cervical cancer screening

Family support

Level of awareness

Level of education

\begin{abstract}
Globally, cervical cancer continues to be a major cause of mortality and morbidity among women with developing countries accounting for more than $86 \%$ of the deaths from the disease. In Kenya, cervical cancer ranks as the second most frequent cancer among women: regrettably, with $80 \%$ of the cases presented during the late stages of the disease when the scope of successful treatment is limited. An opportunity to prevent occurrence of cervical cancer exists through cervical cancer screening for early detection and treatment of precancerous lesions before these develop to cancer. However, only a negligible proportion of women benefit from cervical cancer screening services in developing countries, including Kenya. The purpose of this descriptive survey study was to determine the factors influencing utilization of cervical cancer screening services; and focused on the women seeking maternal and family planning services at Central Provincial General Hospital, Kenya. The study established that, as in most developing countries, utilization of cervical cancer screening services was low, regardless of the women's education level, autonomy in decision making and even good family support. The low level of awareness on the need for screening services and the long waiting time at the clinic for those seeking the services were identified as the two key issues that negatively influenced the utilization of the screening services, It is therefore recommended that the Ministry of Health and other agencies, including individuals of good will, collaborate in designing and implementing awareness campaigns through the media and other appropriate avenues, including one-to-one encounters, targeting both men and women in the communities. It is also recommended that the male partners support their women in accessing this vital life-saving service.
\end{abstract}

Copyright () 2018 Institute of Advanced Engineering and Science. All rights reserved.

\section{Corresponding Author:}

David Macharia,

Open, Distance and eLearning (ODeL) Campus,

University of Nairobi, Kenya

Email: davidmacharia39@ hotmail.com

\section{INTRODUCTION}

Cervical cancer is a disease that affects the reproductive health organ of a woman called the cervix (the organ connecting the uterus and vagina). It is a slow-growing cancer that may take ten (10) years or more to develop. In its early stages of development, cervical cancer may not have any symptom, but the disease can be identified through regular screening. In its late stages, it may present irregular vaginal bleeding, pelvic pain and other symptoms that are common with other reproductive health problems and, as such, may only be confirmed through investigative screening [1].

The primary cause of cervical cancer is Human Papiloma Virus (HPV). Tobacco smoking, many deliveries, long-term hormonal contraceptive use and co-infection with HIV have been identified as cofactors 
necessary for progression from cervical HPV infection to cancer [2]. HPV is sexually transmitted. Its primary prevention strategies are basically two: the first being HPV vaccination and the second being health education for modification of behaviors associated with HPV infection such as risky sexual behaviors, smoking, and many deliveries, among others. Secondary prevention measures involve cervical cancer screening for early detection and treatment of precancerous lesions [3], [4]. A precancerous lesion is abnormal body cells which, if left untreated, may lead to cancer. HPV vaccination reduces cervical cancer incidence by $70 \%$. However, it is only beneficial for women who have not started engaging in sex. It is also expensive and hence unaffordable for most women in low resource situations [5]. This leaves behavior modification and cervical cancer screening as the key alternative preventive approaches.

The natural history of cervical cancer suggests that precancerous lesions start about 10 years or more before cancer develops. Precancerous lesions are treatable when detected early [1]. Therefore, early screening and treatment for such lesions is important for prevention of cancer. According to the American Cancer Society, it is recommended that every woman who is sexually active or is twenty-one (21) or more years of age should have a cervical cancer screening done annually for three (3) consecutive years. The first screening for cervical cancer should be done after the first sexual intercourse or at the age of 21 years, whichever comes first. After 3 years of normal pap smear, the woman can now test less frequently, for example, once every 3 years if she is classified as being at low risk for cervical cancer; however, she should continue yearly pap smear if she is classified as being at high risk [6]. The women classified as of high risk for cervical cancer include those who are HIV positive, those with associated human papilloma virus, those with multiple sexually partners, those with history of other cancers and those with family history of cervical cancer [7], [8].

Specific cervical cancer screening approaches recommended by WHO include pap smear tests, visual tests and tests for HPV infection. Pap smear involves the collection of a specimen from the woman's cervix which is taken to the laboratory for analysis. It takes about a week for the clients to get the results. This type of screening is effective but widely unavailable due to infrastructural constraints. The visual approaches, (visual inspection using acetic acid-VIA) and visual inspection using Lugos Iodine (VILI), are cheap, easy to learn, and are carried out by the health care workers at the clinic and do not require laboratory infrastructure. The woman gets the results immediately. This method is more appropriate and has been recommended for screening and treatment for precancerous conditions in low-resource settings [9], [10].

The trick then, as happens at the Provincial General Hospital in Nyeri, Kenya, is to integrate cervical cancer screening services in the already existing maternal and child health programs, mainly in the family planning clinics. Both pap smear and visual tests are used as the screening approaches with visual test being the primary method that is carried out by nurses working in the family planning clinic. Pap smear is carried out occasionally, when the doctors recommend.

Evidence from all over the world confirms the high relationship between high morbidity and mortality from cervical cancer with non-participation of women in cervical cancer screening programs and low screening coverage among the eligible population, be it for the first screening or for the recommended regular repeat screening [11], [12]. However, and as would be expected, levels of participation in the screening programs differ a lot between developed and developing countries. The developed countries report high percentage of participation in cervical cancer screening of about $86 \%$ and a follow up rate of $76 \%$ within 3 years after initial screening [13], [14]; resulting in high levels of reduced cumulative mortality rates. On the other hand, cervical cancer continues to be a major public health threat to women in many low and medium resourced countries, that include Kenya, amounting to over $80 \%$ of the world cervical cancer deaths [15], [16]; this arising from lack effective cervical screening program, low utilization of the limited screeining program, and failure to participated in the recommended follow up screening test [17], [18].

Studies from around the world have identified several key factors that influence cervical screening behaviors amongst women. A closer examination of the identified factors suggests that reasons for low utilization of cervical screening are basically the same in both developed and developing regions of the world. These identified factors constitute the objectives of this study thus, ensuring that the study contributes to available literature in this crucial area, besides suggesting strategies that would contribute the prevention and reduction of cervical cancer.

\section{RESEARCH METHOD}

The study adopted a descriptive survey design and utilized a quantitative research approach by use of a structured questionnaire with close ended questions to enable collection of quantitative data on the study's four independent variables. Also, and as expected for this kind of study, extensive review of relevant literature was undertaken with the view to establishing the key variables whose analysis would give the study a global relevance.

Factors Influencing Utilization of Cervical Cancer Screening Services... (Gichogo Agnes Wangechi) 
The target population comprised women aged between 15 and 60 years seeking maternal health services at the Maternal Child Health/Family Planning (MCH-FP) Clinic at Central Provincial General Hospital in Nyeri in the month of June 2012, when the data was collected. The MCH-FP clinic serves an average of 920 women per month [19] who formed the target population of this study. A sample of $30 \%$ of the target population was randomly selected by systematic picking every fourth $\left(4^{\text {th }}\right)$ client who came to the clinic, thus ensuring every woman an equal and independent chance of being included in the study. Out of the grand total of 290 questionnaires that were used in the study, 287 of them were returned, amounting to a high response rate of $98.97 \%$.

\section{RESULTS AND DISCUSSION}

The results' analysis is on each of the four objectives of the study and is based on data sourced from the 287 returned questionnaires. The study findings are then reviewed against those from similar studies around the world as found in literature review.

\subsection{Influence of women's level of education}

This section of the study captures information on the highest level of formal education achieved by the respondents. The women's education level was then cross tabulated with the dependent variable, namely utilization of cervical cancer screening services, to establish the relationship between these two variables. This cross tabulation is necessary because, according to the United Nations World Development Report [20], education is an essential component to human health whereby households with more education enjoyed better health. Women in developing countries tend to be poorly educated; a fact that has profound ramifications on total quality of their lives, including both in accessing healthcare and in health-seeking behavior. Also, as the rest of this section shows, other studies around the globe have recorded a positive association between education level and utilization of cervical cancer screening services among women.

\subsubsection{Respondents level of education}

Respondents were requested to indicate their highest level of formal education. Their responses are given in Table 1. As Table 1 shows, the study group consisted of well-educated women with three quarters of them having attained secondary education and above; and only a tiny proportion $(4.9 \%)$ of the women with no formal education.

Table 1. Respondents' Level of Education

\begin{tabular}{lll}
\hline Education level of respondents & Frequency & Percentage \\
\hline None & 14 & 4.9 \\
Primary level & 57 & 19.9 \\
Secondary level & 139 & 48.4 \\
Tertiary level & 77 & 26.8 \\
Total & 287 & 100.0 \\
\hline
\end{tabular}

\subsubsection{Influence of education level on utilization of cervical cancer screening services}

A cross tabulation of the respondents' education level was done against the number of those who reported to having had previous testing for cervical cancer, as shown in Table 2. Table 2 shows that utilization of cervical cancer screening services among women was low regardless of their level of education. Those women with secondary education or lower had a slightly lower utilization rate of around $25 \%$, against a slightly higher rate of $32.5 \%$ among women with tertiary education.

However, while accepting the fact that generally the utilization of preventive services in Kenya and elsewhere in the developing countries is low, it would be naïve not to appreciate the positive influence of education in the utilization of these services. In this regard, the Kenyan study resonates with similar studies done in Botswana, India and South Africa that confirm that better educated women were more conscious than the less educated ones on utilizing preventive health services [20], [21], [22]. Similarly, a study done in Jamaica by Barba and Juanita in 2004 establishes that of the women who had ever received a pap smear, 64\% of them had a secondary school education as compared to the $41.5 \%$ of the women who had never had a pap smear. The correlation between higher education level and increased cervical cancer screening attendance is also supported by studies in the United States and Mexico [23], [24]. 
Table 2. Education Level versus Utilization of Cervical Cancer Screening Services

\begin{tabular}{lccccc}
\hline \multirow{1}{*}{ Level of education } & \multicolumn{2}{c}{ Previous cervical cancer screening } \\
& Yes & \multicolumn{3}{c}{ No } \\
& Frequency & $\%$ & Frequency & $\%$ & \\
\hline No formal education & 3 & 21.4 & 11 & 78.8 & \\
Primary & 15 & 26.4 & 42 & 73.7 & \\
Secondary & 28 & 25.2 & 111 & 74.8 & \\
Tertiary & 27 & 32.5 & 52 & 67.5 & \\
Total & 71 & & 216 & & 287 \\
\hline
\end{tabular}

\subsection{Women's level of awareness and utilization of cervical cancer screening services}

A woman's level of awareness was measured on four key parameters namely: having ever heard about cervical cancer screening services; knowledge on when to go for the first cervical cancer screening test; knowledge on the role of the screening test; and awareness of risk factors of cervical cancer. These parameters were examined separately and then combined to show the overall level of awareness on cervical cancer screening services.

\subsubsection{Awareness on existence of cervical cancer screening services}

The respondents were asked whether they had ever heard about the existence of cervical cancer screening services; and their responses are recorded in Table 3. As shown in Table 3, majority (68.1\%) of the respondents had previously heard about cervical cancer screening services.

Table 3. Knowledge on Cervical Cancer Screening Services

\begin{tabular}{ccc}
\hline $\begin{array}{c}\text { Previously heard of cervical cancer } \\
\text { screening services }\end{array}$ & Frequency & Percentage \\
\hline Yes & 206 & 68.1 \\
No & 81 & 31.9 \\
Total & 287 & 100.0 \\
\hline
\end{tabular}

\subsubsection{Awareness on the importance of a cervical cancer screening}

The importance of cervical cancer screening is to detect changes on the cervical cells early and treat them before they develop to cancer. Respondents' awareness on this fact was measured by requesting them to identify the role of cervical cancer screening test from a list of given choices, as recorded in Table 4. As Table 4 demonstrates, the respondents' levels of awareness about the importance of a cervical cancer screening were low. Only $18 \%$ of the women knew that the screening was meant to detect the precancerous lesions before they developed into cancer, while a whole $82 \%$ of the women either had misconceptions or they did not know the role of cervical cancer screening.

Table 4. Role of Cervical Cancer Screening

\begin{tabular}{lcc}
\hline \multicolumn{1}{c}{ The role of cervical cancer screening } & Frequency & Percentage \\
\hline To detect cancer & 155 & 54.0 \\
To detect and treat changes on the cervical cells before they become cancerous & 53 & 18.5 \\
To detect any problem in the uterus & 13 & 4.5 \\
To detect HIV and sexually transmitted diseases & 4 & 1.4 \\
Do not know & 62 & 21.6 \\
Total & 287 & 100.0 \\
\hline
\end{tabular}

\subsubsection{Awareness on when to go for cervical cancer screening}

Every woman should have cervical cancer screening when she reaches 21 years of age, then annually for three years, and finaly, every three years. Respondents' awareness of this fact was measured by requesting them to identify when to go for cervical cancer screening from a list of given choices. Their responses are given in Table 5. Table 5 shows that about half of the respondents $(48.4 \%)$, knew when they were supposed to have the cervical cancer screening; while the rest either did not know or had misconceptions. 
Table 5. When to Have Cervical Cancer Screening

\begin{tabular}{lcc}
\hline \multicolumn{1}{c}{ When to have cervical cancer screening } & Frequency & Percentage \\
\hline Initial test at 21 years, annually for 3 years and then every three years & 139 & 48.4 \\
When she is having a uterus related problem & 22 & 7.7 \\
If she has been bleeding irregularly & 7 & 2.4 \\
If she develops irregular unexplained vaginal bleeding & 21 & 7.3 \\
Any time & 14 & 4.8 \\
Do not know & 84 & 29.3 \\
Total & 287 & 100.0 \\
\hline
\end{tabular}

\subsubsection{Awareness on the risk factors of cervical cancer}

Respondents were given a list of risk factors of cervical cancer and then requested to identify the factors known to them. The respondents were then put into three categories depending on the number of risk factors they were able to identify, as shown in Table 6. Table 6 demonstrates a low level of awareness on risk factors with over half (50.9\%) of the respondents identifying only 1-2 risk factors; and only a small proportion (16.7\%) of the respondents able to identify 5-6 risk factors for cervical cancer.

Table 6. Level of Awareness on Risk Factors of Cervical Cancer

\begin{tabular}{lcc}
\hline \multicolumn{1}{c}{ Level of Awareness } & Frequency & Percentage \\
\hline Named 5-6 risk factors & 48 & 16.7 \\
Named 3-4 risk factors & 93 & 32.4 \\
Named 1-2 risk factors & 146 & 50.9 \\
Total & 287 & 100.0 \\
\hline
\end{tabular}

\subsubsection{Respondents' overall level of awareness}

The respondents' overall level of awareness was obtained from scores aggregated from the four indicators described from Table 3 to Table 6. Respondents who had previously heard about cervical cancer screening services scored one point. For the correct answers on the role of cervical cancer screening test and when to undertake the cervical cancer screening, she scored one point for each. In addition, the respondent was assessed on her awareness of the risk factors for cervical cancer. If the respondent mentioned 5-6 risk factors she scored three points. If she mentioned 3-4 risk factors, she scored two points and if she mentions 1-2 risk factors, she scored one point. The maximum possible score was 6 points. The woman's level of awareness was considered very high if she scored 5 points and above; high, when she scored 4 points; low, if she scored 3 points; and very low, if she scored 2 points and below. The respondents' overall level of awareness is captured in Table 7. As Table 7 clearly demonstrates, $83 \%$ of the respondents had a low level of awareness on cervical cancer screening services; while a very small proportion of them $(2.8 \%)$ had very high level of awareness.

Table 7. Respondents' Overall Level of Awareness on Cervical Cancer

\begin{tabular}{lcc}
\hline Level of awareness & Frequency & Percentage \\
\hline Very high & 8 & 2.8 \\
High & 41 & 14.2 \\
Low & 88 & 30.6 \\
Very low & 150 & 52.4 \\
Total & 287 & 100.0 \\
\hline
\end{tabular}

\subsubsection{Relationship of level of awareness and previous screening of cervical cancer}

Much as other factors may influence a woman's decision to seek the screening services, her level of awareness, as detailed in Section 3.2.5, must be a key factor. Accordingly, a cross tabulation was done on the women's overall level of awareness and their previous participation in cervical cancer testing. Their responses are presented in Table 8.

Table 8 shows that there was a significant association of women's level of awareness and their utilization of cervical cancer screening services. Women with very high level of awareness on cervical cancer screening services were better in the utilization of screening services as compared to women with low awareness level. A significantly high proportion of respondents (75\%) with very high level of awareness had been screened for cervical cancer; whereas only a very small proportion $(5.3 \%)$ of respondents with very low levels of awareness had previously been screened for cervical cancer. 
Table 8. Relationship of Level of Awareness and Previous Cervical Cancer Screening

\begin{tabular}{lcccc}
\hline \multirow{2}{*}{$\begin{array}{c}\text { Levels of awareness on cervical cancer } \\
\text { screening service }\end{array}$} & \multicolumn{3}{c}{ Self-reporting on previous cervical cancer testing } \\
& Yes & \multicolumn{3}{c}{ No } \\
\hline Very high & 6 & 75 & 2 & $\%$ \\
High & 25 & 60.9 & 16 & 39.1 \\
Low & 34 & 38.6 & 54 & 61.4 \\
Very low & 8 & 5.3 & 142 & 94.7 \\
Total & 71 & & 216 & \\
\hline
\end{tabular}

This study revealed that over $80 \%$ of the women respondents had low levels of awareness about the role of cervical cancer screening; hence our conclusion that this negatively influenced their utilization of the screening services. Also, and as consistent with studies done in Latin America, Malaysia, Trinidad, Jamaica and Malawi [25], [26], [27], [28], [29], there was a general belief that cervical cancer screening is used to diagnose, rather than to prevent cervical cancer. Accordingly, many women feared being screened in case they are diagnosed with the deadly disease; a revelation that would have adverse social ramifications and stigma.

The overall level of awareness had a significant relationship with previous utilization of cervical cancer screening. In Kenya, for example $75 \%$ of those who had previous screening, returned for more services. This strong relationship between levels of awareness and utilization of services in this study is consistent with similar studies done in Mexico, Uganda and Malawi [29], [30], [31], [32], [33].

Regrettably, in this study, many of the women who were categorized as having a high level of awareness had not presented themselves for cervical cancer screening. This finding is consistent with a study done in Nigeria where $28 \%$ of health workers-who would be expected to have good knowledge on cervical cancer and its ramifications-had never been tested for cervical cancer. As such a behavior is not expected from right-thinking adults, many who are well-educated, other key factors beyond awareness must be at play, as this study reveals.

\subsection{Family support and utilization of cervical cancer screening services}

This section presents the findings on the influence of family support on women's utilization of cervical cancer screening services. The indicators considered include who made decisions about seeking cervical cancer screening services; support from the male partner; and the kind of support given to the woman to enable her to utilize preventive health services, such as cervical cancer screening services.

\subsubsection{Decision making on utilization of cervical cancer screening services}

Respondents were asked to indicate the person who was responsible for making decision in the family on issues relating to maternal health services, such as cervical cancer screening. Their responses are presented in Table 9.

Table 9. Persons Responsible for Making Decision on Seeking Cervical Cancer Screening Services

\begin{tabular}{lcc}
\hline Person responsible for decision making & Frequency & Percentages \\
\hline Self & 187 & 65.2 \\
Male partner & 24 & 8.4 \\
Both self and male partner & 59 & 20.6 \\
Other persons & 17 & 5.9 \\
Total & 287 & 100 \\
\hline
\end{tabular}

Table 9 records a high level of autonomy amongst the study group, even in this male-dominated society. A whole $65.2 \%$ of the women were responsible for their decision to seek the screening services. Male partners' involvement was certainly evident, but at low levels, with only $29 \%$ of the respondents either involving their partners or the males taking the decisions regarding the seeking cervical cancer screening services.

\subsubsection{Relationship of responsibility in decision making and utilization of screening services}

Cross tabulation was done on responsibility for making decisions against utilization of cervical cancer screening services. The results are presented in Table 10. Table 10 reveals that, among the group, the males were key players in their partners' involvement in the utilization of cervical cancer screening services. A combined total of $53.6 \%$ of the women who had utilized the screening services reported that either their 
spouses, or both they and the spouses, had made the decision. This contrasts with the $26.6 \%$ utilization level of women who made the decision on their own.

Table 10. Responsibility for Decisions Making Against Utilization of Screening Services

\begin{tabular}{|c|c|c|c|c|c|}
\hline \multirow{3}{*}{ Responsibility for decision making } & \multicolumn{4}{|c|}{$\begin{array}{c}\text { Previously utilized cervical cancer screening } \\
\text { services }\end{array}$} & \\
\hline & \multicolumn{2}{|c|}{ Yes } & \multicolumn{2}{|c|}{ No } & \\
\hline & Frequency & $\%$ & Frequency & $\%$ & \\
\hline Self & 50 & 26.6 & 138 & 73.4 & \\
\hline Male partner & 8 & 33.3 & 16 & 66.7 & \\
\hline Both self and partner & 12 & 20.3 & 47 & 79.7 & \\
\hline Other persons & 1 & 10 & 9 & 90 & \\
\hline Total & 71 & & 217 & & 287 \\
\hline
\end{tabular}

\subsubsection{Form of support when seeking cervical cancer screening services}

Respondents were requested to indicate the form of support they require when seeking cervical cancer screening services. Their responses are presented in Table 11. Table 11 shows that all the respondents needed support of one kind or another when seeking cervical cancer screening services. The support included finances, escort to the facility, and encouragement to seek the services. Certainly, and again underscoring the importance of the male partner in this culturally-delicate matter, most of the respondents indicated support would come from their male partners.

Table 11. Support Sought When Seeking Cervical Cancer Screening Services

\begin{tabular}{lll}
\hline Form of support given & Frequency & Percentage \\
\hline Financial support & 186 & $64.5 \%$ \\
Escort to the health facility & 29 & $10.1 \%$ \\
Encouragement to seek services & 32 & $11.1 \%$ \\
No support required & 41 & $14.2 \%$ \\
Total & 287 & 100 \\
\hline
\end{tabular}

A closer look at the evidence in this section brings up several interesting facts. Even though majority of the respondents had high levels of education; had the autonomy to make decisions about when to seek the needed cervical cancer screening services; and had support from their male partners, a high proportion of them did not seek the services. This contrasts with studies done in India and Pakistan where women's autonomy was found to improve uptake of reproductive health services [21], [34].

This low level of utilization of services among study women who had all these positive factors in their favour, perhaps should be blamed on both their low level of awareness and the fear of the stigma associated with seeking preventive health services as opposed to curative ones.

\subsection{Accessibility of cervical cancer screening services}

This section presents findings on the accessibility of cervical cancer screening services at Central Provincial General Hospital in Nyeri. The indicators investigated include distance the women covered to the health facility; perception about the cost; and the amount of time the client had to wait at the clinic to receive the service.

\subsubsection{Distance from the hospital}

Respondents were requested to indicate the distance they had to cover to reach the Provincial General Hospital. The responses are as indicated in Table 12. Table 12 shows that majority (65.3\%) of the women accessing services from the MCH/FP clinic travelled no more than five (5) kilometres to reach the hospital; and only a small proportion $(3.1 \%)$ had to cover more than $10 \mathrm{~km}$ to the hospital. The distance to the hospital was then cross tabulated with previous utilization of cervical cancer screening services, and the results are as shown in Table 13.

As shown in Table 13, distance to the health facility had no significant relationship with previous participation in cervical cancer testing, as virtually $70 \%$ of the respondents recorded no previous participation in cervical cancer testing regardless of the distance to the hospital. 
Table 12. Distance Covered to Reach the Hospital

\begin{tabular}{lll}
\hline Distance covered & Frequency & Percent \\
\hline $0-5 \mathrm{~km}$ & 188 & 65.3 \\
$6-10 \mathrm{~km}$ & 91 & 31.6 \\
Over $10 \mathrm{~km}$ & 9 & 3.1 \\
Total & 287 & 100.0 \\
\hline
\end{tabular}

Table 13. Distance to the Hospital and Utilization of Cervical Cancer Screening Services

\begin{tabular}{lccccc}
\hline \multirow{2}{*}{ Distance to the hospital } & \multicolumn{5}{c}{ Self-reporting on previous cervical cancer testing } \\
& Yes & \multicolumn{4}{c}{ No } \\
& Frequency & $\%$ & Frequency & $\%$ & \\
\hline $0-5 \mathrm{~km}$ & 41 & 21.8 & 147 & 78.2 & \\
$6-10 \mathrm{~km}$ & 28 & 30.8 & 63 & 69.2 & \\
$>10 \mathrm{~km}$ & 2 & 22.2 & 7 & 77.8 & 2287 \\
Total & 71 & & 217 & & 28 \\
\hline
\end{tabular}

\subsubsection{Cost of the cervical cancer screening services}

The respondents were requested to rate the cost of cervical cancer screening services on a scale of very expensive, expensive and fair. Table 14 records their responses. As shown in Table 14, only a small number of the respondents $(15 \%)$ rated the charges for screening services as expensive.

Table 14. Responses on Cost of Cervical Cancer Screening Services

\begin{tabular}{lcc}
\hline \multicolumn{1}{c}{ Rating of charges for screening } & Frequency & Percentage \\
\hline Very expensive & 11 & 3.8 \\
Expensive & 32 & 11.1 \\
Fair & 169 & 58.9 \\
No response & 75 & 26.1 \\
Total & 287 & 100.0 \\
\hline
\end{tabular}

\subsubsection{Relationship of cost rating and utilization of cervical cancer screening services}

Cross tabulation was done on cost rating against utilization of cervical cancer screening services. The results are presented in Table 15. Table 15 shows that cost had limited influence on utilization of cervical cancer screening services. Of the 169 respondents who rated the charges as fair, only $34.9 \%$ of them reported to have utilized the available screening services. In contrast, $45.5 \%$ of the respondents who rated the charges as very expensive indeed utilized the services.

Table 15. Comparison between Cost Rating and Utilization of Cervical Cancer Screening

\begin{tabular}{lccccc}
\hline \multirow{2}{*}{ Cost of Screening Services } & \multicolumn{2}{c}{ Self-reporting on previous cervical cancer testing } \\
& Yes & \multicolumn{4}{c}{ No } \\
& Frequency & $\%$ & Frequency & $\%$ & \\
\hline Very expensive & 5 & 45.5 & 6 & 54.5 \\
Expensive & 6 & 18.8 & 26 & 81.3 & \\
Fair & 59 & 34.9 & 110 & 65.1 & \\
No response & 1 & 1.3 & 75 & 98.3 & \\
Total & 71 & & 216 & & 287 \\
\hline
\end{tabular}

\subsubsection{Waiting time at the clinic before receiving cervical cancer screening services}

The respondents were requested to record the time they spent at the clinic waiting to receive the screening services. Their responses appear in Table 16. As shown in Table 16, a significant 55\% of the respondents reported that they had to wait for $1 / 2 \mathrm{hr}$. and more to access cervical screening services at the Provincial General Hospital. This reported waiting time was then cross tabulated with previous cervical cancer screening. The results are as presented in Table 17.

As shown in Table 17, a shorter waiting time was closely associated with a higher utilization of cervical screening services. About half of the respondents who identified the waiting time to be 10-20 minutes utilized the cervical cancer screening services. The utilization rate becomes poorer and poorer as the waiting time increased to the extent that those who identified a waiting time of more than an hour never utilized the services. 
Table 16. Waiting Time to Receive Cervical Cancer Screening

\begin{tabular}{lcc}
\hline Waiting time before receiving cancer testing & Frequency & Percentage \\
\hline $10-20$ minutes & 75 & 26.1 \\
$21-30$ minutes & 55 & 19.2 \\
30 minutes- $1 \mathrm{hr}$ & 63 & 22.0 \\
More than $1 \mathrm{hr}$ & 94 & 32.8 \\
Total & 287 & 100.0 \\
\hline
\end{tabular}

Table 17. Comparison of Waiting Time and Utilization of Cervical Cancer Screening Services

\begin{tabular}{lccccc}
\hline \multirow{2}{*}{ Waiting time } & \multicolumn{5}{c}{ Self-reporting on previous cervical cancer testing } \\
& Yes & \multicolumn{4}{c}{ No } \\
& Frequency & $\%$ & Frequency & $\%$ & \\
\hline 10-20 minutes & 35 & 46.7 & 40 & 53.3 & \\
21-30 minutes & 18 & 32.7 & 37 & 63 & \\
31-60 minutes & 9 & 17 & 54 & 83 & \\
1 hour & 0 & 0 & 94 & 100 & 287 \\
Total & 71 & & 217 & & 28 \\
\hline
\end{tabular}

The study notes that majority (65.3\%) of the women accessing services from the MCH/FP clinic travelled no more than five (5) kilometres to reach the hospital and only $22 \%$ of the women travelled for 10 $\mathrm{km}$ or more. Despite this fact, $70 \%$ of the respondents recorded no previous participation in cervical cancer screening regardless of the distance to the hospital. This finding contrasts studies done in Mexico [35]; South East Asia, [36]; and Western Kenya, [37]; that point to the long distances travelled by clients as negatively influencing their utilization of the available screening services.

The study has also shown that there was no significant association between direct cost of the cervical cancer tests and the utilization of the service. This contrasts with findings from studies in Western Kenya, [37]; and from Mexico, [23]; that established that cost of services had an influence on women's utilization of appropriate health care services.

Finally, the section considered the influence of waiting time on the utilization of the cervical cancer screening services. The study has established a direct link between these two variables in that the longer the waiting time at the clinic, the less the chances of utilizing available screening services. These findings are consistent with those from a qualitative study done in Malawi [29] in which the women reported that they were willing to be screened; however, they had not done so because of the long waiting at the clinic. In other words, women, who, most likely, had taken time off from other responsibilities to rush to the clinic, may not be willing to spend a lot of time queuing. This scenario is relevant especially in the case of screening services where the women lining up would not be experiencing any relevant health problems.

\subsection{Utilization of cervical cancer screening services}

This section wishes to establish whether those women who had previously undertaken a cervical cancer test had returned for subsequent tests and the reasons why they did so.

\subsubsection{Previous screening for cervical cancer}

Respondents were asked if they had previously undertaken a cervical cancer test. Their responses are presented in Table 18. Table 18 captures the low uptake of cervical cancer screening test among the study group. As already recorded about the low utilization rate, only $24.7 \%$ of the respondents had previously been screened for cervical cancer.

Table 18. Previous Participation in Cervical Cancer Screening

\begin{tabular}{ccc}
\hline Ever been screened for cervical cancer & Frequency & Percentage \\
\hline Yes & 71 & 24.7 \\
No & 216 & 75.3 \\
Total & 287 & 100.0 \\
\hline
\end{tabular}

\subsubsection{Cervical cancer screening within the last 3 years}

The women who have undergone an initial test should have learnt the importance of follow up tests. Hence, respondents who had previously tested for cervical cancer were asked if they had undertaken further tests within the last three years. Their responses are as indicated in Table 19. As shown in Table 19, of the 71 respondents who had ever been screened for cervical cancer, a sizeable proportion, equal to $88.7 \%$, had 
undertaken a screening within the past 3 years. This action by the respondents attests to the positive role of awareness, besides other factors, in utilizing the screening services.

Table 19. Responses on Cervical Cancer Screening Within the Last 3 Years

\begin{tabular}{ccc}
\hline Screened within the last 3 years & Frequency & Percentage \\
\hline Yes & 63 & $88.7 \%$ \\
No & 8 & 11.3 \\
Total & 71 & 100.0 \\
\hline
\end{tabular}

\subsubsection{Reasons for undertaking subsequent cervical cancer screening}

Respondents who had previously been screened for cervical cancer were asked to record why they had undertaken this subsequent initiative. Their responses are recorded in Table 20. Table 20 shows that majority $(70.4 \%)$ of the women who had undergone cervical cancer test undertook subsequent testing to confirm their health status, while another $23.9 \%$ was following the doctors' advice. This again attests to the vital role of awareness, and equally, that of those in the know to advise the women to undertake the screening services.

Table 20. Reasons for Undertaking Subsequent Cervical Cancer Screening

\begin{tabular}{lcc}
\hline \multicolumn{1}{c}{ Reasons for doing subsequent cancer test } & Frequency & Percentage \\
\hline Needed to know I was still healthy & 50 & 70.4 \\
Had a problem with my womb & 4 & 5.7 \\
Was requested by a doctor to do so & 17 & 23.9 \\
\hline
\end{tabular}

\section{CONCLUSION}

In conclusion, we record the key findings of the study: findings that generally concur with similar studies around the globe. The study has confirmed the very low cervical cancer utilization rate around the globe. In contrast to what might be expected, formal education of the participating women was found to have only limited influence in the utilization of available services. This is probably due to the low levels of awareness on issues relating to cervical cancer screening; especially the mistaken notion of cervical cancer screening as a curative rather than a preventive measure. With such mistaken notion, unless one has issues with her organs, it made little sense to seek screening services. The study has also established the central role of the male partner in form of encouragement and support, be it financial or psychological. This involvement is crucial particularly in the patriarchal societies where men have a dominant role especially over their women's health seeking decisions. Such partner's support is equally important as the subject in question involves a disease found in the woman's private parts hence, seeking the screening services could lead to the mistaken belief that the concerned woman has been involved in immoral behavior. Finally, the study has established that women are less likely to be screened for cervical cancer if, for whatever reason, waiting time at the clinic is lengthy. Such lack of patience is reasonable for women who are forced to sacrifice time from family or job-related tasks; more so, since most times the women seeking the services have no obvious health problem.

The conclusion of this study points to three simple facts. First, cervical cancer is easy to manage. Secondly, while certainly not belittling the crucial health side, we need to accept that the disease is basically a societal problem: and, as with all societal issues, prevention and management of this disease cannot be left to the concerned women and health personnel only. It demands all members of the society working together for the common purpose; and as experience from all the world has proven; such joint efforts usually meet their declared objectives. It is with this confidence that the study offers the following recommendations that would ensure conquest of cervical cancer among women, especially through enhanced and effective utilization of screening services.

It is recommended that the Government of Kenya, through the Ministry of Health; the civil societies, religious and other community groups; and individuals of good will, collaborate in designing and implementing awareness campaigns on cervical cancer; and equally, the vitality of utilizing cervical cancer screening services. This should be done through the media, religious gatherings, women groups and chiefs' barazas (meetings) and other appropriate avenues, including one-to-one encounters, targeting both men and women in the communities.

It is recommended that the men, especially the partners, learn about cervical cancer, especially the role of the screening services. Such an exposure should lead to men giving their women the needed space in 
form of encouragement and support, be it financial or psychological, to undergo the needed cervical cancer screening and treatment, if the latter is found necessary.

It is recommended that both male and female doctors and nurses familiarize themselves with the facts of the disease; and then, in whatever health encounter, intensify appropriate health education on the crucial role of cervical cancer screening services for individuals or groups of clients during appropriate clinical contacts. Especially the involved women health workers, particularly the young ones, should themselves be role models and hence use this fact to convince their clients to also participate.

Health facilities should integrate cervical cancer screening services, especially pap smear and visual tests, in the already existing maternal and child health programs; an action that would guarantee privacy and reduction of stigma to the women accessing the services.

The Government of Kenya should consider employing more nurses and doctors to improve the staffing levels in the hospitals to reduce waiting time by clients; an action that would certainly enhance utilization of cervical cancer screening services.

\section{ACKNOWLEDGEMENTS}

Our appreciations go to close circle of friends especially Dr. Juma Mwangi, the Provincial Gynecologist, and Nelly Maina, the Reproductive Health Trainer, Nyeri for their unwavering support and encouragement. Also, we are grateful to our colleague and friend, Dr. Stephen Otieno, of Africa Capacity Alliance (ACA), Nairobi, for his support in formatting this paper for publication.

\section{REFERENCES}

[1] Spencer, J., Deadly Disease and Epidemics: Cervical Cancer: Infobase Publishers, Chelsea House, New York, 2007.

[2] WHO/ICO, Information Center on HPV and Cervical Cancer (HPV Information Center): Human Papilloma Virus and Related Cancers in Kenya; Summary Report, 2010, Retrieved from http://www.who.int/hpvcenter/en (accessed on 24th February 2012)

[3] WHO/ICO, Information Centre on HPV and Cervical Cancer (HPV Information Centre): Human Papillomavirus and Related Cancers in Africa, Summary Report 2009, 2009, Retrieved from http:// www.who.int/hpvcentre. (Accessed on 23 March 2010).

[4] Minoz Franceschi S., Bosch C., Moreno V., Herrero R., Smith J. S, Shah K., Meijer C and Bosch X, Role of Parity and Human Papilloma Virus in Cervical Cancer: The IARC Multicentric Case-Control Study: Lancet 359, 10931101, 2002.

[5] Braaten A., and Laufer M.R., "Human Papilloma Virus, HPV-related Disease and HPV Vaccine." Reviews in Obstetrics and Gynaecology, 1 (1) :2-10, 2008.

[6] Saslow, D., Boetes, C., \& Burke, W., "American Cancer Society: Guidelines for Early Detection of Cancer" Cancer Journal for Clinicians 18 (7). 58-72, 2008.

[7] Maggwa, B.N, Hunter, D.J., Mbugua, S., Tukei, P., Mati, J, K., "The Relationship Between HIV Infection and Cervical Intraepithelial Neoplasia Among Women Attending Two Family Planning Clinics in Nairobi," Kenya: AIDS .7:733-738, 1993.

[8] Kapiga, S, H., Msamanga, G, I., Spiegelman, D., Mwakyoma, H., Fawzi, W, W, Hunter, D; "Risk Factors for Squamous Intraepithelial Lesions Among HIV-1 Seropositive Women in Dar es Salaam, Tanzania," International Journal of Gynecology and Obstetrics 67: 87-94, 1999.

[9] Belinson J, L., Pretorius R. G., Zhang, W. H., Wu L.Y., Qiao Y.L, Elson P. "Cervical Cancer Screening by Simple Visual Inspection after Acetic Acid," Obstetrics and Gynecology 98 (3), 441-4, 2001.

[10] Wesley, R., Sankaranarayanan, R., Mathew, B, Chandralekha, B., Aysha- Beegum, A., Amma N.S., "Evaluation of Visual Inspection as a Screening tTest for Cervical Cancer," British Journal of Cancer 75 (3): 436-440, 1997.

[11] Buskens I, Bradley J. Women's Perspectives on Cervical Cancer Prevention Procedures: Engender Health. New York, 2002.

[12] Janerich, D., Hadjimichael, O., Schwartz, E., Lowell, D., Meigs, J., Merino, M., Flannery, J. \& Polednak, "A. The Screening Histories of Women with Invasive Cervical Cancer in Connecticut," American Journal of Public Health 85 (6):791-794, 1995

[13] Nasca, P., Ellish, N., Caputo, T., Saboda, K., \& Metzger, B., “An Epidemiologic Study of Pap Screening Histories in Women with Invasive Carcinomas of the Uterine Cervix" New York State Journal of Medicine, 91 (4): 152-156, 1991.

[14] McKee, D. Strategies to Improve Follow-up of Abnormal Pap Smears, Archives of Family Medicine, 32 (6): $574-$ 577, 1995.

[15] Marcus, A., Crane, L., Kaplan, C., Reading, A., Savage, E., \& Gunning, J., Improving Adherence to Screening Follow-up among Women with Abnormal Pap Smears: Results from a Large Clinic-based Trial of Three Intervention Strategies: Archives of Family Medicine, (30) 6:216-229, 1992.

[16] International Agency for Research on Cancer, Cervix Cancer Screening: Handbooks of Cancer Prevention: Lyon, France, IARC Press, 2005. 
[17] Ferlay, J., Bray, F., Pissani, P., Parkin, D., Cancer Incidence, Mortality and Prevalence, Worldwide, Lyon, France IARC Press, 2002.

[18] Carey, P., Gjerdingen, D. Follow-up of Abnormal Papanicolaou Smears among Women of Different Races, Journal of Family Practice. 37(6): 583-587, 1993.

[19] Lewis M. Situational Analysis of Cervical Cancer in Latin America and the Caribbean: Washington, DC: 7 Pan American Journal, 2004.

[20] Central Province, Kenya, Annual Reproductive Health Report, 2010.

[21] Sankaranarayanan R, Rajkumar R, Arrossi S, Theresa R, Esmy P. O, Mahe C, et al. Determinants of Participation of Women in a Cervical Cancer Visual Screening Trial in Rural South India: Cancer Detect Prevention. 27: $457-$ 65, 2003.

[22] Nene B, Jayant K, Arrossi S, Shastri S, Budukh A, Hingmire S. Determinants of Women's Participation in Cervical Cancer Screening Trial, Maharashtra, India: Bulletin of the World Health Organization, 85:264-272, 2007.

[23] Bradley J, Risi L, Denny L. Widening the Cervical Cancer Screening Net in a South African Township: Who Are the Underserved? Health Care Women Int. (2004); 25:227-41, 2004.

[24] Bingham A., Bishop A., Coffey P., Winkler J., Bradley J., Dzuba I., and Agurto, I., Factors Affecting Utilization of Cervical Cancer Prevention Services in Low-resource Settings. Salud Publica, Mexico 45 (3), 408-S416, 2003.

[25] Fletcher, H. Screening for Cervical Cancer in Jamaica. Caribbean Health. 2:9-11, 1999.

[26] Agurto I. Bridging Distances: Preventive Services and Women's Concerns. Program on Non-Communicable Diseases. Division of Disease Prevention and Control. Pan American Health Organization Washington, DC, 2001.

[27] Bessle P, Maung, A., and Jolly, P, "Factors Affecting Uptake of Cervical Cancer Screening among Clinic Attendees in Trelawny," Jamaica Cancer Control 14: 4, 2007.

[28] Chingang, L, C., Bischof, U., Andall-Brereton, G., 'Have a Pap Smear!', "Doctors, their Clients and Opportunistic Cervical Cancer Screening,” International Journal of STD and AIDS.;16,233-236, 2005.

[29] Wong, L, P., Wong, Y. L., Low, W. Y., Khoo, E. M., Shuib. R. "Knowledge and Awareness of Cervical Cancer and Screening Among Malaysian Women Who Have Never Had a Pap Smear" A Qualitative Study. Singapore Medical Journal 50 (1) 49, 2009.

[30] Fort, V.K., Makin, M.S., SieglerA.J., Ault, K., and Rochat, R. "Barriers to Cervical Cancer Screening in Mulanje, Malawi” A Qualitative Study. East African Medical Journal 10:62-65, 2011.

[31] Mutyaba, T., Faxelid, E., Mirembe, F., and Weiderpass, E. Influences on Uptake of Reproductive Health Services in Nsangi Community of Uganda and Their Implications for Cervical Cancer Screening, 2007.

[32] Lazcano-Ponce E, C, Castro R, Allen B, "Barriers to Early Detection of Cervical-Uterine Cancer in Mexico,"” Journal of Women's Health 8: 399-408, 1999.

[33] Hsia J, Kemper E, Kiefe C, Zapka J, Sofaer S, Pettinger M, "The Importance of Health Insurance as a Determinant of Cancer Screening Evidence from the Women's Health Initiative" Prev Med. 31:261-70, 2000.

[34] Chamberlain J. "Reasons that Some Screening Programmes Fail to Control Cervical Cancer: Hakama M, Miller AB, Day NE, (Editors). Screening for Cancer of the Uterine Cervix. Lyon” International Agency for Research on Cancer/International Union against Cancer, pp. 161-8, 1986.

[35] Saleem S, Bobak M. Women's Autonomy, Education and Contraception Use in Pakistan: A National Study: Reproductive Health; 2:8, 2005.

[36] Babar, T, S., Juanita H. "Health Seeking Behaviour and Health Service Utilization in Pakistan: Challenging the Policy Makers." Journal of Public Health 27(1), 49-54, 2004.

[37] Islam A, Tahir M. Z., Health Sector Reform in South Asia (2002): New Challenges and Constraints: Health Policy, 60:151-169, 2002. 